\title{
CAUSE-ORIENTED INVESTIGATION OF THE FIRE INCIDENTS IN AUSTRIAN WASTE MANAGEMENT SYSTEMS
}

\section{Thomas Nigl *, Wolfgang Rübenbauer and Roland Pomberger}

Montanuniversitaet Leoben, Department of Environmental and Energy Process Engineering, Chair of Waste Processing Technology and Waste Management, Franz-Josef-Straße 18, A-8700, Leoben, Austria

Article Info:

Received:

12 July 2019

Revised:

11 November 2019

Accepted:

18 November 2019

Available online:

6 December 2019

Keywords:

Waste fire

Conflagration cause

Lithium-ion-battery

\begin{abstract}
In many European and North American countries, stakeholders and interest groups endeavour to improve fire prevention in the industry of waste management, disposal and recycling. Despite the industry's commitment to increasing safety and fire prevention measures, incidents have peaked in recent years, causing numerous problems: Environmental pollution, potential loss of resources, facility infrastructure and contractual partners, even higher insurance rates and deductibles. The most severe consequence which is recently spreading is the looming peril of a total loss of insurance cover.This paper discusses the comprehensive results of the survey and analysis of 285 fire incidents in the waste industry of Austria that have occurred within the recent decade. First, the historical development and reasons for the current increase in waste fires are stated, revealing waste-specific fire patterns such as self-ignition and the expanding range of potential ignition sources. Second, the statistical correlation between the probability of fire incidents and seasonal or climatic factors is shown. Third, the paper presents specific findings regarding the most commonly affected waste streams as well as the distribution patterns of ignition sources and causes. For example, most fire incidents occur in storage and transport areas (52.6\% and $22.8 \%$ ). Finally, probable driving forces are indicated and the potential development of risks and hazards from future waste fires are shown. The paper reveals a fundamental understanding of the conditions and incipiency of fires in waste management, disposal and recycling as well as gaps in our present knowledge that compellingly require further research.
\end{abstract}

\section{INTRODUCTION}

In many European and North American countries, stakeholders and interest groups endeavour to improve fire prevention in the industry of waste management, disposal and recycling. Despite the industry's commitment to increase safety and fire prevention measures, incidents have peaked in recent years (Nigl and Pomberger 2018, Messenger 2017, Fogelman 2018), causing numerous problems.

These problems are ranging from environmental pollution due to uncontrolled and hazardous emission, complaints by local residents and neighbours, via the potential loss of resources, facility infrastructure and contractual partners, through to the increase of insurance rates and deductibles. Even more, as a severe consequence the total loss of insurance cover is looming and recently spreading in Austria and Germany.

\subsection{Background}

The recently growing numbers of waste fires is concerning because their origins are little understood, nor is the topic of fire incidents and fire protection commonly discussed in scientific literature. There have been several studies of individual waste-specific causes of fire mainly from self-ignition (e.g. Holzer 2007; Ibrahim et al. 2013). But the problem of waste fires has rarely been addressed as a whole. Their causes and influence factors are often only assumed based on empirical values rather than on scientifically sound findings. General lack of knowledge about causes, circumstances and progress of waste fires has to be attested.

In recent years, batteries have presented a new hazard to waste management systems. Both increasing amounts of battery-powered devices and increased use of lithiumbased high-energy batteries (both primary and secondary cells) have been observed. As a consequence, the number of accidents and claimed incidents related to portable batteries (especially lithium-based batteries) has steeply risen. Future volumes will continue to increase the potential risk of fire incidents across the whole end-of-life chain (from collection to storage and transport to treatment or recovery). 


\subsection{Study objectives}

This study was conducted in the BAT-SAFE interdisciplinary research project, aiming at assessing risks and hazards of portable batteries in waste management systems. The purpose of this study is to qualitatively and quantitatively examine previous incidents of fire to (1) identify potential risk factors or dangerous combinations of factors and (2) evaluate waste specific fire causes (e.g. the role of lithium batteries as sources of fire). Findings gained in quantitative research into fire causes are included.

The following questions were posed:

- What are the causes of waste fires, which are most relevant and how do they develop over time?

- When and where do these fires originate in waste management companies?

- What are relevant influence factors (e.g. season, daytime, weather, temperature) and in what way are they related?

Are fire incidents more frequent or longer on weekends?

How do weather patterns, seasonal or climatic conditions affect fire behavior?

- What are the respective drivers (influence factors)?

\section{METHODOLOGY}

The survey plan of this study followed two approaches including (1) collection and analysis of data via a stakeholder questionnaire and (2) collection and analysis of data from online press and media.

For the first approach, a detailed questionnaire was developed in order to gain data from personal, telephone and email-based questioning. The questionnaire covered about 30 different parameters, including specific data on fire conditions, waste streams involved, data of fire protection systems installed and of the waste management and treatment processes.

For the second approach, a detailed press and media research (including publicly available sources) was carried out to record as many incidents having occurred in waste management companies as possible (including recycling and waste disposal companies), drawing on the most relevant internet search engines (such as Google and Bing) as well as the search functions of relevant Austrian online press and media. A previously defined search term catalogue was used (see supplementary material, in German). In addition, the snowball principle was applied to obtain further incidents of fire. Moreover, the reports of (voluntary or professional) fire brigades and archives of online portals of Austrian fire services were searched for waste fires (for examples, see supplementary material).

In some cases attempts were made to obtain data on identified waste fires from the local voluntary fire brigade by phone-call. Unfortunately, this approach very often collided with matters of data privacy and protection.

Collection was followed by a revision of the recorded data, essentially concerning the elimination of double and false records. Where appropriate, missing data was com- pleted with the help of other sources. Many parameters, however, had to be left blank or unknown because data for the defined parameters were often not available in public sources.

Unknown or not clearly assignable waste fractions have been designated as 'waste not defined'. The fire duration and amounts of damage were then plotted on an ordinal scale to account for any inaccuracies in the raw data collected. One reason for this approach was the relatively frequent and inaccurate indication of the amounts of damage, such as a 'six-digit damage', referring to financial damages somewhere between 100,000 and 999,999 Euros.

Subsequent data analysis, including descriptive statistics, linear regression and general linear modelling, was carried out using MS Office (Excel) and the statistical programmes STATISTICA and R.

After the assessment of long-term statistical data for the monthly mean temperature and precipitation in Austria, data for the city of Linz were applied to the model as average values.

To compare data collected in this project with reference values, the data sets were (1) standardised to the population size of the respective region, referencing one million capita, and (2) fire causes allocated to a defined scheme (see Table 4 for results).

The system boundaries of the study's research were set as follows:

\section{Spatially: Austria}

- Temporally: 10 years (11/2007-11/2017)

- Availability: Data given by stakeholders (approach 1); publicly available data (approach 2)

The following data and parameters were collected for each fire incident:

- Date (derived: weekday, month, year, season)

- Time of fire alarm and time of fire extinction (derived: fire duration)

- Place, postal code (derived: federal state)

- Aggregates/facility/plant type

- Waste fraction

- Cause of fire

- Amount of damage

- Casualties or injured persons

In order to illustrate the spatial distribution of fire incidents, the coordinates of known facilities were obtained from providers of online topographic maps. When the facility or site of fire was not known, the central coordinates of the affected community were used.

\section{RESULTS AND DISCUSSION}

The first approach regarding the collection and analysis of data obtained by a stakeholder questionnaire yielded no quantitatively assessable result. Due to different reasons, such as (1) concerns about privacy and data protection, (2) worries about adverse consequences in dealing with authorities or insurance providers or (3) missing or incomplete internal fire reporting systems, the response rate by stakeholders was very low. Less than 20 of more than 150 
stakeholders addressed in the questionnaire responded by providing data on specific incidents.

For this reason, only the results of the second approach regarding the collection and analysis of data from online press and media is discussed in the following.

\subsection{Spatial and temporal distribution pattern}

In total, 659 incidents of fire were collected during the media survey. Of these, 285 cases (43\%) are accounted for by the waste industry (companies dealing with waste management, waste disposal and recycling). 65 other cases $(10 \%)$ concerned waste fires in companies from other sectors (commerce and industry) and 309 cases (47\%) involved waste fires in public and private sectors, mainly concerning fires at private collection sites and public waste bins. The focus of this study is on the 285 waste fires in the waste industry.

Figure 1 shows the geographical distribution of incidents collected from Austrian companies for the purposes of this project (waste management, disposal and recycling industry). The presented distribution pattern superficially matches the distribution pattern of the population in Austria and is also constrained by topology (e. g. sparsely populated alpine regions in western and central Austria).

The annual amount of fire incidents has increased over time during the surveyed period of ten years, both seasonally and annually (Figure 2). Apart from the high amount of unknown causes of fire, the figure shows that the diversity of known causes has increased over the years. This may be explained by the composition of different household waste fractions having more diversified in recent years (Nigl and Pomberger 2018).

The relative amount of self-ignition has risen since 2014, although self-ignition has been a serious problem in the mid and late 2010s already and was addressed both by scientific research and by suitable and applicable countermeasures (e.g. Pomberger et al. 2006, Schoßig et al. 2010, Held et al. 2011).

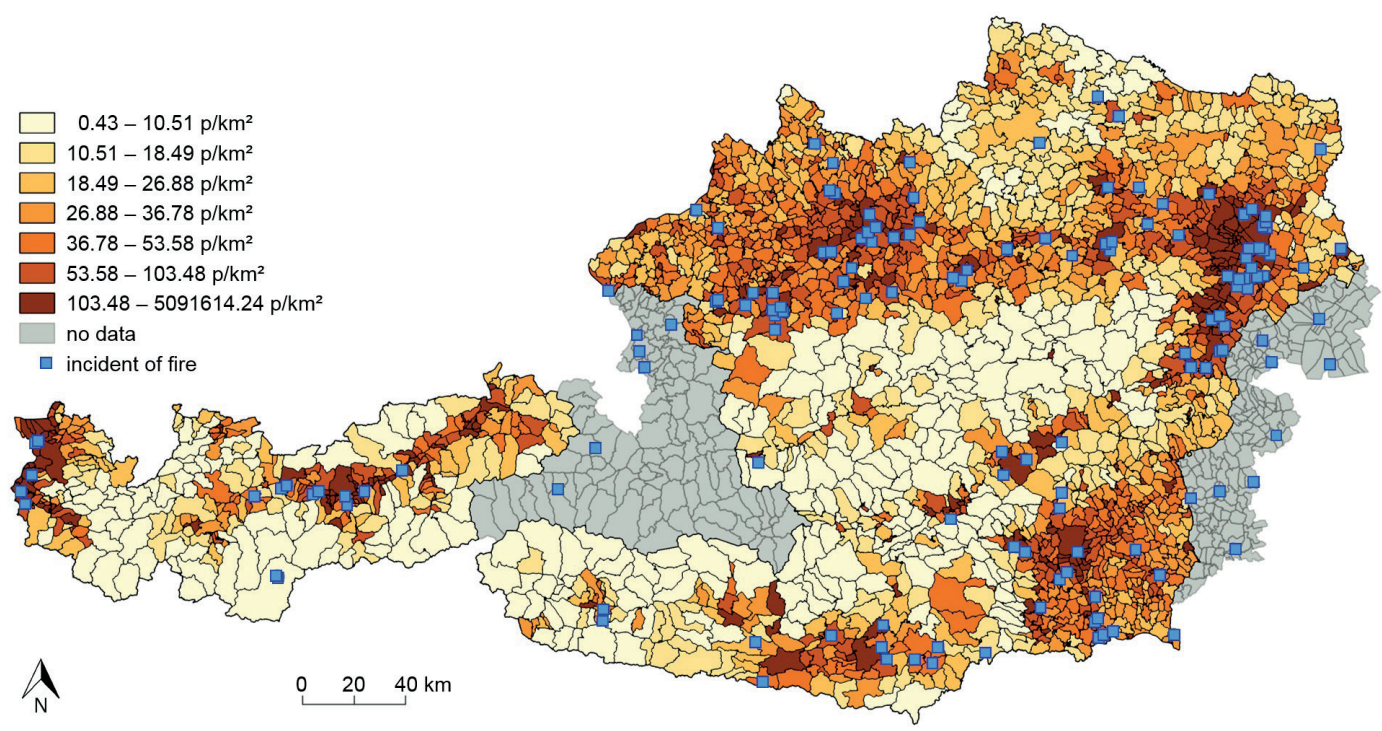

FIGURE 1: Geographical distribution of population density and incidents of fire in waste industry $(n=285)$; chart of population density according to ODVIS-AT (2014).

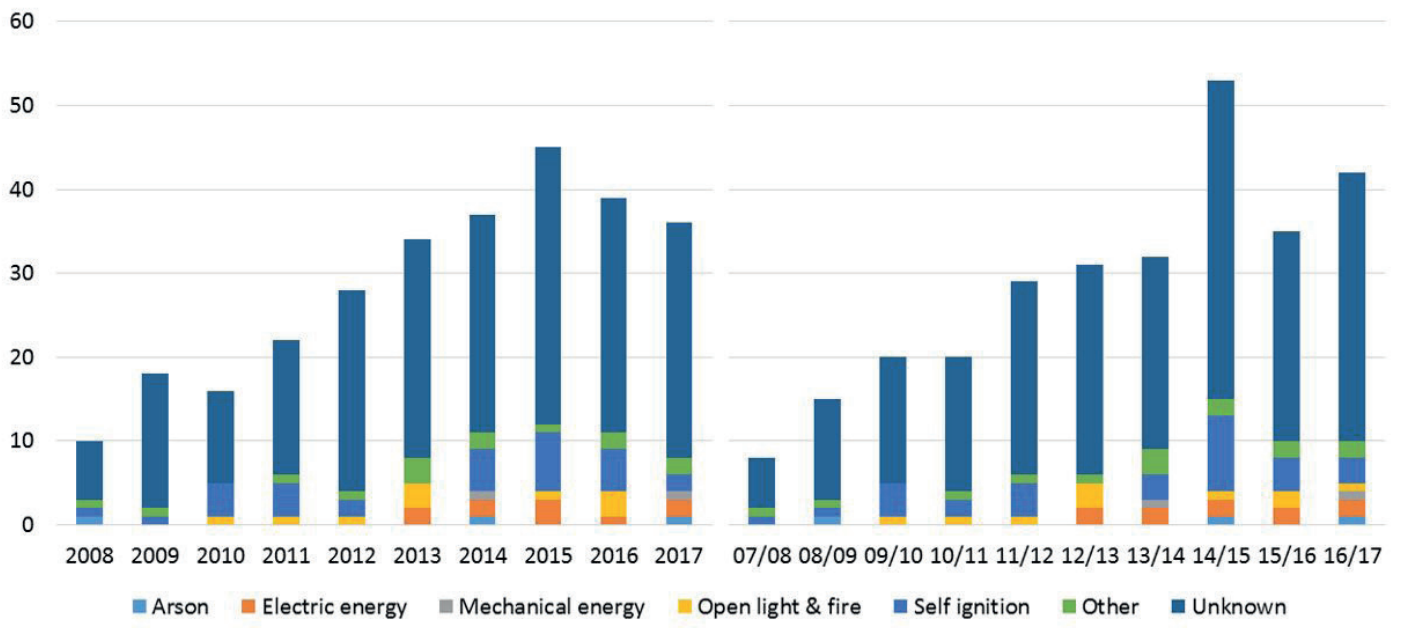

FIGURE 2: Annual and seasonal distribution of incidents of fire including causes of fire $(n=285)$. 
There are two plausible reasons for this phenomenon: Unlike arson or fire originating from technical or electrical faults, waste-specific causes of fire are often hard to identify (Nigl and Pomberger 2018). Fire investigators may incline to conclude on self-ignition as the cause of fire, if there is no evidence for any other origin. On the other hand, waste fires involving or caused by lithium-ion batteries are increasing in recent years and (like other causes of fire) are often difficult to identify, leading to a mistaken conclusion on self-ignition.

Comparable data for waste fires can be found in references from the United Kingdom, Sweden, Austria and the German federal states of Saxony and North-Rhine Westphalia.

The Environmental Agency investigated waste fires in the United Kingdom from 2001 to 2013 (Oliver and Brown 2014). Ibrahim et al. (2013) considered cases of fire occurring in permanent and temporary waste storage facilities (including waste for incineration, digestion and composting) in Sweden between 2000 and 2010, recorded by means of stakeholder surveys. In addition, data on cases of fire from two parliamentary inquiries in the German federal state of Saxony are available (Sächsisches Staatsministerium für Umwelt und Wirtschaft 2007, Sächsisches Staatsministerium für Umwelt und Wirtschaft 2015). LANUV (2016) surveyed waste fires in North-Rhine Westphalia in the period of 2011 to 2015. Comparative data on fire incidents in Austria date from the period of 2004 to 2007 (Holzer 2007).

Except for the United Kingdom, whose numbers are already at a very high level, the rates of fire incidents are rising over the respective period (Figure 3 ).

From a methodical point of view, it should be noted that these data sets are based on different survey methods. The location parameters of the data sets (presented in Table 1), however, are distributed in a similar way despite different statistical populations and survey methods.

The month-by-month graph of incidents in Austria is shown in Figure 4. The months of March to August are well above the theoretical average of 23.75 fire incidents per month while September to February are significantly below.
TABLE 1: Location parameter for annual amounts of fire incidents per million capita.

\begin{tabular}{l|cccccc} 
Region & Minimum & Maximum & Median & Mean & SD \\
\hline $\begin{array}{l}\text { United } \\
\text { Kingdom }\end{array}$ & 4,16 & 6,72 & 5,50 & 5,41 & 0,83 \\
\hdashline Sweden & 0,67 & 3,10 & 1,66 & 1,76 & 0,93 \\
\hdashline Austria & 1,20 & 5,21 & 2,39 & 2,90 & 1,30 \\
\hdashline Saxony & 1,86 & 4,65 & 3,06 & 3,07 & 0,92 \\
\hdashline $\begin{array}{l}\text { North-Rhine } \\
\text { Westphalia }\end{array}$ & 1,25 & 2,44 & 1,76 & 1,84 & 0,50 \\
\hline
\end{tabular}

An analysis of the influence of seasonal or climatic factors (monthly mean temperature or monthly average precipitation) shows a statistically significant correlation to the number of fire incidents. The number of fires per month correlates with the monthly mean temperature and monthly mean precipitation (data for Linz adopted for Austria), indicating that fires are more common in warm and rainy summer months than in winter months. The correlation is modest with an $R^{2}$ of 0.62 (for precipitation) and $R^{2}$ of 0.54 (for temperature) but statistically highly significant $(p=0.002$ and $p=0.006$ ). Since these two variables have a high degree of combined explanatory value (autocorrelation and high correlation to each other, see Figure 4), their individual influence on the dependent variable in a combined consideration (general linear model) is not significant.

The statistical correlation can be explained both by higher microbial activity and by a higher probability of exothermic chemical-physical processes triggered in hotter environments. The months of March and September are not perfectly in accord with the trend. An effect of their role as transitional periods between winter and summer may be assumed. A higher sample size in the course of further surveys or the observation of an extended survey period could help clarify this issue.

The distribution of fire incidents across days of the week shows that fires scatter around an average value of 40.7 from Monday to Saturday, only Sunday has to be considered a low outlier (Figure 5). In addition, long-burning incidents (speaking of long fire durations) are distributed

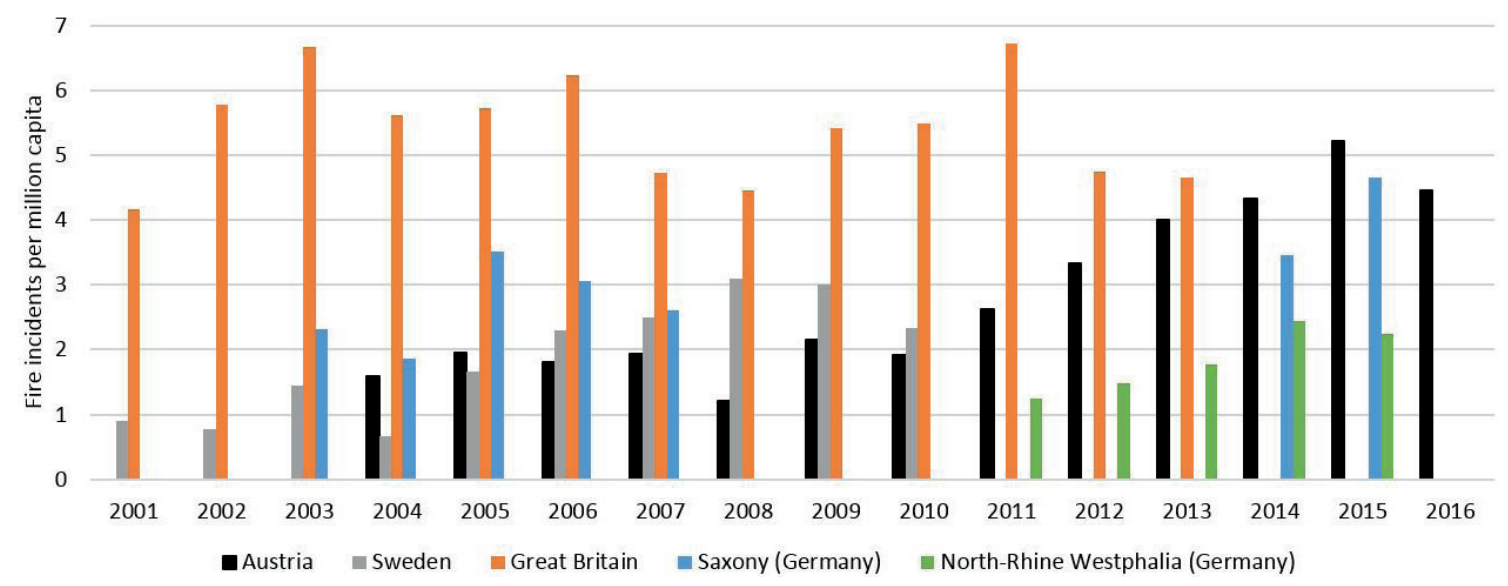

FIGURE 3: Comparison of the annual amount of fire incidents per million capita for Austria (data from this study and literature) and different European regions (data from literature). 


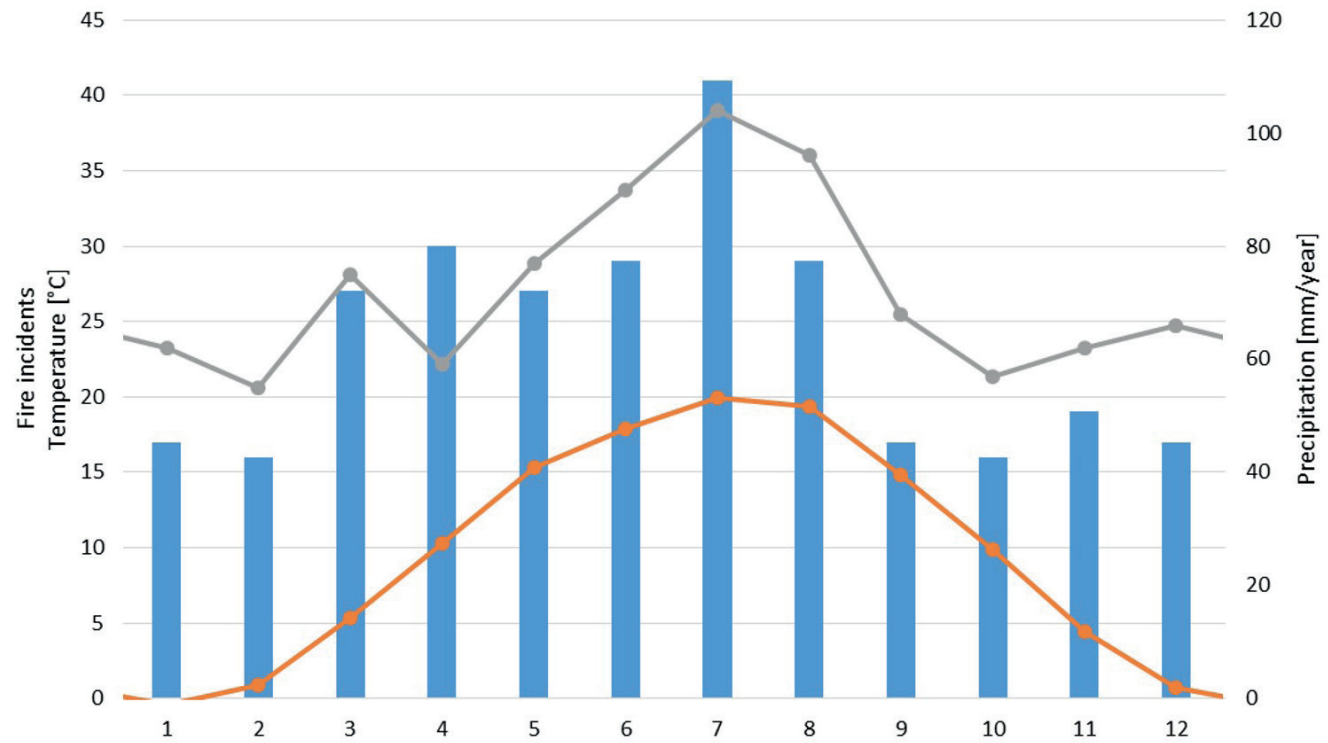

FIGURE 4: Monthly distribution of fire incidents compared to mean temperature and mean precipitation per month $(n=285)$.

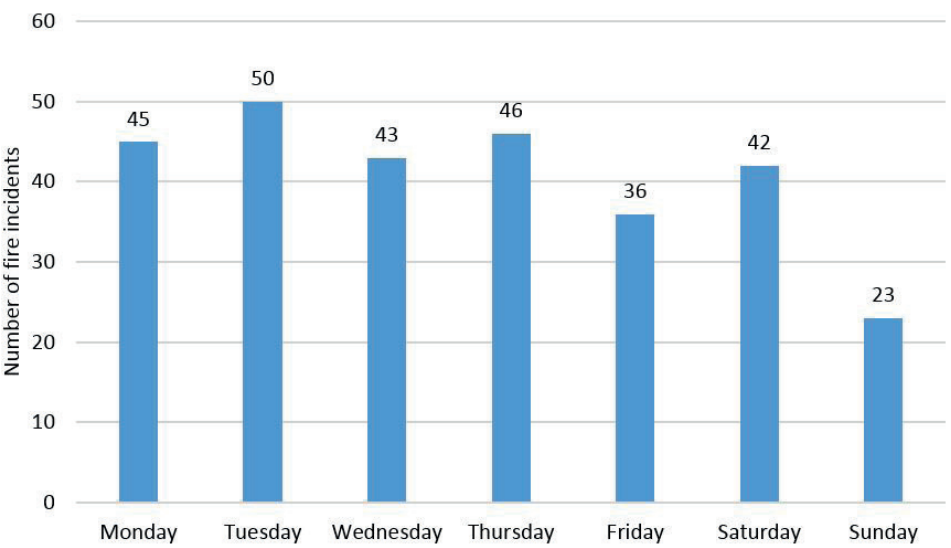

FIGURE 5: Distribution of fire incidents across days of the week $(n=285)$.

equally across the days of the week. Hence, the common assumption that (long-burning) incidents are more common on weekends when staff does not act as an early detection unit could not be confirmed. On the contrary, the results suggest that the probability of fire incidents is related to the operating activities of the facilities, meaning that fires are more frequent on workdays.

\subsection{Local distribution pattern}

In 227 cases, rather detailed information about the location of the fire ignition was available whereas in 58 cases, the locations was unknown or only available at plant or facility level (see Table 2). Especially with regard to the distinction between input and output storage areas, a precise allocation of cases was not possible because required information was not available.

Note that the terms for aggregates and plant/facility areas are based on the respective sources of information. Correctness of the given information was not always verifiable and therefore the data is not fully consistent (e.g. waste processing vs. recycling facility or waste treatment vs. sorting plant).

From an investment point of view, there is a concentration of fire incidents on shredders (a total of 30 cases) and storage areas (about 150 cases). According to the experience of individual plant operators, the relative amount of fires associated with crushing processes is significantly higher (even up to $50 \%$ of the cases may occur during crushing processes).

Another 65 cases of fire relate to the transport areas and can be assigned to collection or transport vehicles (18 cases) and waste containers (47 cases). In the latter case, there is no evidence for whether these incidents should rather be assigned to the transport or to the storage area.

\subsection{Distribution of waste fractions and causes of fire}

The distribution of the cases of fire across waste types or waste fractions involved is shown in Table 3.

Slightly more than $40 \%$ of the incidents could not be assigned to a specific waste type or fraction (waste not defined). Municipal solid waste accounts for 69 of the 285 cases (24\%), including 41 cases of residual waste (house- 
TABLE 2: Distribution of fire incidents across waste facilities and their areas/sections $(n=285)$

\begin{tabular}{|c|c|}
\hline Specific locations of fire origin & 227 \\
\hline Aggregates / facility areas & 54 \\
\hline Waste bunkers & 6 \\
\hline Delivery halls & 2 \\
\hline Feeding/intake hoppers & 1 \\
\hline Exhaust extraction and filtration systems & 3 \\
\hline Conveyors & 9 \\
\hline Shredders, shredding facilities & 30 \\
\hline Waste turner, waste mixer & 3 \\
\hline Storage areas & 108 \\
\hline Outdoor storage areas & 31 \\
\hline Storage (boxes) & 31 \\
\hline Storehouses & 29 \\
\hline Bales, bale storages & 3 \\
\hline Waste piles & 6 \\
\hline Baler, press containers & 8 \\
\hline Transport areas & 65 \\
\hline Collection and transport vehicles & 18 \\
\hline Waste containers & 47 \\
\hline Unspecific locations of fire origin & 43 \\
\hline Recycling facility & 10 \\
\hline Waste treatment facility & 8 \\
\hline Waste sorting plant & 8 \\
\hline Waste recovery facility & 2 \\
\hline Composting plant & 1 \\
\hline Municipal waste collection center & 6 \\
\hline Landfill & 8 \\
\hline Unknown location of fire origin & 15 \\
\hline Total sum & 285 \\
\hline
\end{tabular}

hold waste), 17 cases of bulky waste and 11 cases of commercial waste. In 7 cases (separately collected), spent batteries could be identified as the burning waste fraction. Another 15 times there was no certain waste involved in the fire because these cases were caused by technical defects.

Table 4 shows a comparison between identified causes of fire and (1) waste-specific causes of fire according to Holzer 2007, Sächsisches Staatsministerium für Umwelt und Wirtschaft 2007, Sächsisches Staatsministerium für Umwelt und Wirtschaft 2015 and LANUV 2016 and (2) the distribution of fire causes in other industrial and commercial sectors in Upper Austria (BVS OOE 2018). It is observed that causes of fire in waste industry are often unclear or unknown (26-78\%) and more specific than in other sectors. Fires caused by lightning strokes, heat energy and devices or tank explosions, on the other hand, are no issue in waste industry while self-ignition is much more frequent.

Observing the average fire duration is relevant as it is directly related to the potential amount of damage, as shown in Figure 6. The size of the bubbles in the graph corresponds to the number of incidents.
TABLE 3: Distribution of fire incidents across involved waste fractions $(n=285)$.

\begin{tabular}{|c|c|c|}
\hline \multicolumn{3}{|l|}{ Waste fractions } \\
\hline Waste (not defined) & 117 & $41.1 \%$ \\
\hline Residual household waste & 41 & $14.4 \%$ \\
\hline Bulky waste & 17 & $6.0 \%$ \\
\hline Commercial waste & 11 & $3.9 \%$ \\
\hline Organic waste & 16 & $5.6 \%$ \\
\hline Waste metals & 18 & $6.3 \%$ \\
\hline Waste plastics & 13 & $4.6 \%$ \\
\hline Waste paper & 10 & $3.5 \%$ \\
\hline Other waste material (not defined) & 6 & $2.1 \%$ \\
\hline Batteries & 7 & $2.5 \%$ \\
\hline Waste electrical and electronic equipment & 3 & $1.1 \%$ \\
\hline Other hazardous waste (not defined) & 3 & $1.1 \%$ \\
\hline End-of-life vehicles & 2 & $0.7 \%$ \\
\hline End-of-life tires & 1 & $0.4 \%$ \\
\hline Grinding sludge or dust & 2 & $0.7 \%$ \\
\hline Refuse derived fuel & 1 & $0.4 \%$ \\
\hline Shredder light fraction & 1 & $0.4 \%$ \\
\hline Workshop waste & 1 & $0.4 \%$ \\
\hline No waste & 15 & $5.3 \%$ \\
\hline
\end{tabular}

The correlation shows that waste fires lead to a higher level of damage the longer the fire burns. The graph shows that two scenarios will not plausibly occur: Long-burning incidents causing a small amount of damage and quickly extinguished incidents causing a high amount of damage. This result also corresponds to the model presented by Richter (2007) on the correlation between amount of damage and progress of the fire.

Finally, when examining the size of incidents, the survey showed that waste fires have a typical pyramidal-shaped distribution with a lot of incipient fires, a medium amount of small fires and a few large fires. However, the 285 fires included in this study have to be considered the tip of the iceberg because incipient and small fires frequently occur in waste companies and are often not recorded in (online) press and media.

\section{CONCLUSIONS}

The investigation of the recent ten years of fire incidents in the Austrian waste industry was conducted in this study by two different approaches. Due to privacy and data protection concerns, worries about adverse consequences and missing or incomplete internal fire reporting systems, the first approach yielded no assessable result. The results of the second approach showed a clear correlation between the number of fires per month with the average temperature and the average precipitation per month. The influence of rather short-term weather phenomena on the occurrence and incipiency of waste fires, however, requires further investigation. 
TABLE 4: Comparison of causes of fire in waste industry and other industry sectors.

\begin{tabular}{|c|c|c|c|c|c|c|c|}
\hline \multirow{3}{*}{$\begin{array}{l}\text { Region } \\
\text { Period } \\
\text { Branch }\end{array}$} & \multirow{2}{*}{$\begin{array}{c}\text { Austria } \\
2007-17\end{array}$} & \multirow{2}{*}{$\begin{array}{c}\text { Austria } \\
2003-07\end{array}$} & \multicolumn{2}{|c|}{ Saxony (DE) } & \multirow{3}{*}{$\begin{array}{c}\text { NRW (DE) } \\
2011-14\end{array}$} & \multirow{2}{*}{\multicolumn{2}{|c|}{$\begin{array}{c}\text { Upper Austria } \\
2012-16\end{array}$}} \\
\hline & & & 2003-07 & 2014-15 & & & \\
\hline & \multicolumn{4}{|c|}{ Waste management, disposal and recycling } & & Industry & Commerce \\
\hline Source (data adopted) & this study & Holzer 2007 & \multicolumn{2}{|c|}{ SMUL 2007 \& 2015} & LANUV 2016 & \multicolumn{2}{|c|}{ BVS OOE 2018} \\
\hline Number of fire incidents & $n=285$ & $\mathrm{n}=58$ & $n=57$ & $n=33$ & $\mathrm{n}=94$ & $n=163$ & $n=1018$ \\
\hline 1. Lightning stroke & & & & & & $7 \%$ & $19 \%$ \\
\hline 2. Self-ignition & $11 \%$ & $17 \%$ & $23 \%$ & $36 \%$ & $33 \%$ & $7 \%$ & $4 \%$ \\
\hline 3. Heat energy \& devices & & & $2 \%$ & & & $6 \%$ & $17 \%$ \\
\hline 4. Mechanical energy & $1 \%$ & & $2 \%$ & $6 \%$ & & $22 \%$ & $12 \%$ \\
\hline 5. Electrical energy & $4 \%$ & & $2 \%$ & $3 \%$ & & $25 \%$ & $17 \%$ \\
\hline 6.Open light and fire & $4 \%$ & $2 \%$ & $5 \%$ & & $4 \%$ & $9 \%$ & $15 \%$ \\
\hline 7. Tank explosion & & & & & & $1 \%$ & \\
\hline 8. Arson & $1 \%$ & & $33 \%$ & $6 \%$ & $9 \%$ & $3 \%$ & $10 \%$ \\
\hline 9. Other & $5 \%$ & $3 \%$ & $7 \%$ & $3 \%$ & $29 \%$ & $2 \%$ & $1 \%$ \\
\hline 10. Unclear, unknown & $75 \%$ & $78 \%$ & $26 \%$ & $45 \%$ & $26 \%$ & $18 \%$ & $6 \%$ \\
\hline Total & $100 \%$ & $100 \%$ & $100 \%$ & $100 \%$ & $100 \%$ & $100 \%$ & $100 \%$ \\
\hline
\end{tabular}

With regard to locations most affected by fires, a distinct focus on storage areas was found. In treatment facilities, fire incidents will likely take place in shredders.

The widespread assumption that fires increasingly occur on weekends (when staff members do not act as early detection units) could not be confirmed since long-burning fires are distributed equally across the days of the week.

There is also an evident correlation between the duration of the fire and the amount of damage. Therefore, the industry resp. the companies should aim to reduce not only the number of incidents but also the average fire duration to minimise the extent of damage. Recommendable measures include early fire detection methods or other fire prevention (e.g. automatic extinguishing systems).

Comparing the results of this study with data from the United Kingdom, Sweden, Saxony and North-Rhine Westphalia shows that high levels of incidents in waste management companies are not limited to nations. Rather, the waste industry as a whole is prone to fires (Nigl and
Pomberger 2018), requiring more attention paid to industry-specific measures in order to control this hazards in the future.

The rising relevance of batteries as sources of ignition (fire cause) did not reflect in this study, although, experiences of individual plant operators suggest exactly the opposite. On the one hand, there were only a few incidents publicly reported where separately collected batteries were involved in fires. On the other hand, misplaced lithium batteries were rarely identified as source of ignition in other waste streams. Waste-specific fire causes are often difficult to identify and fires caused by batteries often falsely allocated to self-ignition.

Finally, this study shows the ceiling of specific knowledge about fires in the waste industry. Further research is imminent and inevitable to highlight the high relative amount of unknown parameters such as causes of fire, involved waste fractions or pinpointing the exact locations of fires.

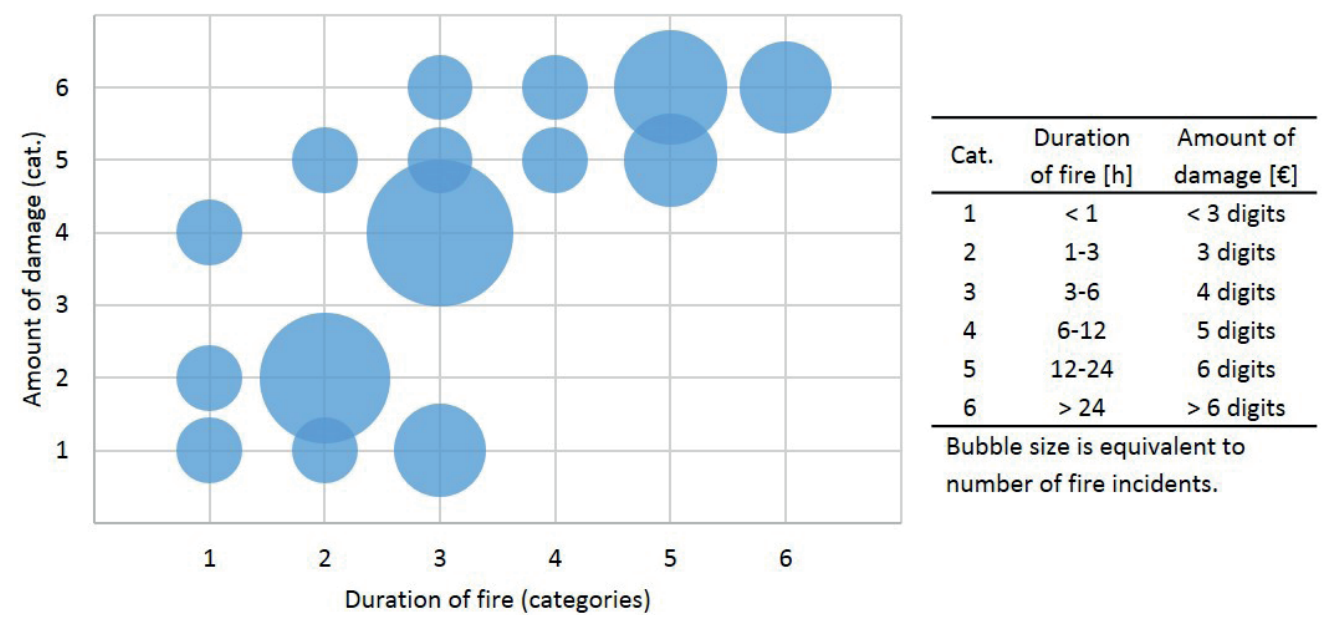

FIGURE 6: Bubble graph showing the amount of damage depending on the fire duration $(n=30)$. 


\section{REFERENCES}

Fogelman, R. (2018). Fire Safety - Is the recycling industry facing a fire epidemic? Recycling Product News. URL: https://www.recyclingproductnews.com/article/27240/is-the-recycling-industry-facing-a-fire-epidemic.

Held K., Kern H., Raupenstrauch H. (2011) Brand- und Explosionsschutz bei der Produktion und Lagerung von Ersatzbrennstoffen. BHM Berg- und Hüttenmännische Monatshefte 156 (9) 357-362.

Holzer C. [ed.] (2007). Anforderungen an die Zwischenlagerung von heizwertreichen Abfällen. Bundesministerium für Land- und Forstwirtschaft, Umwelt und Wasserwirtschaft, Vienna, Austria.

Ibrahim M.A., Alriksson S., Kaczala F. and Hogland W. (2013). Fires at storage sites of organic materials, waste fuels and recyclables. Waste Management \& Research 31 (9), p. 937-945.

LANUV (Landesamt für Natur, Umwelt und Verbraucherschutz Nordrhein-Westfalen) [ed.] (2016). Brandereignisse in Abfallbehandlungsanlagen - Abschlussbericht und Schluss-folgerungen der Landesregierung. LANUV-Fachbericht 68, Recklinghausen, Germany.

Messenger, B. (2017) In Depth: Fighting Fire at Waste \& Recycling Plants - Best Practice to Reduce \& Tackle Fires at Waste Facilities. Waste Management World.

Nigl T. and Pomberger R. (2018). Brandgefährlicher Abfall - Über Risiken und Strategien in der Abfallwirtschaft. Conference-Paper, Recy \& Depo Tech 2018, Leoben, Austria.
ODVIS-AT (2014) Population density in Austria based on data collected by the project ODVIS-AT. Salzburg University of Applied Sciences.

Oliver P. and Brown S. (2014). Waste Industry Fires Report. Environment Agency. Stourport, Great Britain. URL: https://www.mrw. co.uk/Journals/2014/04/01/q/e/c/Waste-industry-fires-report. pdf.

Pomberger R., Curtis A., Raupenstrauch H. (2006). Brandschutztechnische Untersuchungen bei der Lagerung von Ersatzbrennstoffen für die Zementindustrie. In: Kozmiensky K.J. et al. [Hrsg.] (2006) Zwischenlagerung von Abfällen und Ersatzbrennstoffen. TK Verlag Karl Thomé- Kozmiensky, Neuruppin, Germany.

Richter B. [ed.] (2007). Anlagensicherheit. Hüthig. Heidelberg, Germany.

Sächsisches Staatsministerium für Umwelt und Wirtschaft (2007). Brände bei Recyclingfirmen in Sachsen. Dresden, Germany. URL: http://www.gruene-fraktion-sachsen.de/fileadmin/user_upload/ Kleine_Anfragen/4_Drs_9504_-1_1_12.pdf.

Sächsisches Staatsministerium für Umwelt und Wirtschaft (2015). Brandfälle in Abfall-behandlungs- und Recyclinganlagen und Deponien seit März 2014. Dresden, Germany.

Schoßig J., Berger A., Malow M., Krause U. (2010). Beurteilung und Verhinderung von Selbstentzündung und Brandgasemission bei der Lagerung von Massenschüttgütern und Deponiestoffen. Forschungsbericht 291. Hrsg. v. BAM Bundesanstalt für Materialforschung und -prüfung. Berlin, Germany. 